\title{
A complete review on a complete medicinal plant: Cucurbita
}

\author{
T. Sampath Kumar*1, C. Jothimanivannan², V. Sasi Kumar ${ }^{2}$, M. Vanitha ${ }^{3}$ \\ ${ }^{1}$ Department of Pharmacognosy, ${ }^{2}$ Department of Pharmaceutical Chemistry, ${ }^{3}$ Department of \\ Pharmacology, SS Institute of Pharmacy, Sankari, Salem 637301, India
}

Received: 22-07-2021 / Revised Accepted: 24-08-2021 / Published: 01-09-2021

\begin{abstract}
Cucurbita is a best source of potassium and beta-carotene, which is a carotenoid that converts to vitamin A. The medicinal plant has many major secondary metabolites, triterpenoids, diterpene, Cucurbita glycosides, cucurbitosides, carotenoids etc. Number of pharmacological reaches has done to report hepatoprotection, inhibit benign prostatic hyperplasia, antioxidant, anticancer, antimicrobial, antiinflamatory, antidiabetic, and antiulcer activities of Cucurbita. It has more therapeutic potential. Our review article focusses to give compilation of Origin, Nomenclature, History, cultivation, various names, various species, composition and pharmacological uses. This article can give potential research areas to explore next, and to formulate new formulation in allopathy and some traditional medicine system.
\end{abstract}

Keywords: Pumpkin, Cucurbita, Phytoconstituents, Anti-Cancer, Anti Diabetic, Anti-Ulcer activity

\section{INTRODUCTION}

From the ancient history to $21^{\text {st }}$ century in many parts of the world and India, plants, animals and other nature things have many influences on our culture and human civilization Since the beginning of civilization, human beings have devoted plants and such plants are protected as a genetic resource and used as edible, medicine, provender, dietary supplements, fertilize and in every other way and those will helps to enhance scope $e^{[1]}$ of pharmacognosy, Cucurbita is one of those plants. Species of Pumpkins, Cucurbita pepo or Cucurbita mixta are from the same family as cucumbers, squash and other vine-dwellers that have seeds. Pumpkins are flavoursome and have multi nutrients. Vitamin A in pumpkins is the major vitamin helps to maintain healthy skin and immunity, while fiber used to balance blood glucose levels. balance blood pressure and muscle relaxant to safeguard the circulatory system. Its fat content is low, but it contains anti-inflammatory omega-3 fatty acids in the form of alpha-linolenic acid. Cucurbita possess anti-cancer activity. It also has anti diabetic activity, it helps to maintain rhythm of heart beat and protects heart.The other name of Cucurbita is cupping glass, cucurbitula and also latin meaning Gourd. It will help to

Address for Correspondence: Mr. T. Sampath Kumar, Department of Pharmacognosy, SS Institute of Pharmacy, Sankari, Salem 637301; E-mail: sampath21gaucher@gmail.com

How to Cite this Article: T. Sampath Kumar, C. Jothimanivannan, V. Sasi Kumar, M. Vanitha. A complete review on a complete medicinal plant: Cucurbita. World J Pharm Sci 2021; 9(9): 223-229.

This is an open access article distributed under the terms of the Creative Commons Attribution-NonCommercialShareAlike 4.0 International License, which allows adapt, share and build upon the work non-commercially, as long as the author is credited and the new creations are licensed under the identical terms. (cc) EY-NC-SA 
formulate a polyherbal ${ }^{[2]}$ diabetic tablet because of its synergism ethnobotany claim with some traditional herbs like horse gram ${ }^{[3]}$ etc.

\section{ORIGIN}

Archaeologists discovered the oldest domesticated pumpkin seeds in the Oaxaca Highlands of Mexico. Pumpkins are believed to have originated in Central America over 7,500 years ago. One of the first American pumpkin recipes was included in John Josselyn's New-England's Rarities Discovered, published in the early 1670s. The earliest known record of human domestication and consumption of pumpkins comes from Mexico, where remnants of seeds and squashes have been found in the Oaxaca valley and Tamaulipas dwellings - perhaps dating as far back as $8750 \mathrm{BCE}$ and $7000 \mathrm{BCE}$, respectively. Additional findings in Missouri (4000 BCE) and Mississippi (1400 BCE) are also relevant.

\section{HISTORY}

Many culinary uses for pumpkin have developed over time. There is some evidence to suggest that the ancient Aztecs enjoyed pumpkin seeds as a quick but satiating snack. Native Americans roasted long strips of pumpkin to eat, while European colonists are responsible for the origin of pumpkin pie - they would cut off the pumpkin top, remove the pumpkin's seeds, and fill it with honey, milk, and seasonings before baking it in hot ashes. The sap and pulp of pumpkins has long been used throughout parts of Central and North America as treatment for burns. Seeds have also been used by the Menominee people as a diuretic. Dry strips of pumpkins were sometimes used by Native Americans, who wove them into household mats.

\section{TAXONOMIC HIERARCHY}

- Kingdom - Plantae Planta, Vegetal, plants

- Subkingdom - Viridiplantae green plants

- Division - Tracheophyta vascular plants, tracheophytes

- Class

- Magnoliopsida

- Order

- Cucurbitales

- Family

- Cucurbitaceae

- Genus

- $\quad$ Species

- Cucurbita L. gourd

- maxima

List of taxa in the genus Cucurbita and their natural distributions is mentioned in Table 1. OTHER NAMES:

$\begin{array}{llll}\checkmark & \text { English } & - & \text { Pumpkin } \\ \checkmark & \text { Gujarati } & - & \text { kolu } \\ \checkmark & \text { Hindi } & - & \text { kaddu } \\ \checkmark & \text { Kannada } & - & \text { kumbalakai } \\ \checkmark & \text { Marathi } & - & \text { Lal bhopala } \\ \checkmark & \text { Tamil } & - & \text { Poosanikai } \\ \checkmark & \text { Telugu } & - & \text { Gummadikai } \\ \checkmark & \text { Bengali } & - & \text { Saphurii }\end{array}$

$\checkmark$ Malayalam - ChakkeraKumpalan.

\section{VEGETATIVE PLANT DESCRIPTION:}

Cucurbita plants has thick stems but they are creepers and it is an annual herb Cucurbita plants is an annual herb. The root is very deep up to $40 \mathrm{~cm}$ and $5 \mathrm{~m}$ long. The leaves are alternate, simple, palmately veined, basally cordate, apically obtuse, broader, stiff to soft pubescent, and perfectly dentate. They have Adventitious roots, usually grown at nodes to support survival. The stems have white hairs and stems are grown up to $10 \mathrm{~m}$ long. The petioles are sparsely pubescent, $5-20 \mathrm{~cm}$ long, and estipulate. The plant has tendrils at $90^{\circ}$ to the leaf axil; these are less pubescent, coiled, and 3 to 6 branched.

\section{FLOWER DESCRIPTION}

Cucurbita have unisexual flowers, (male and female on the same plant) that's why they are called as monoecious, blossoming single actinomorphic flowers (10-20 cm across). But they sustain for a day with blossom. For pollination they secrete pleasant sweet nectar with aroma to attract bees. The campanulate calyx contains white pubescence and bears, 5 free sepals; each sepal is linear-lanceolate and $0.5-2 \mathrm{~cm}$ long. The yellow to orange corolla is tubular, at least $5 \mathrm{~cm}$ long and broad, 5-parted with reflexed petals that are ovate, apically obtuse, and marginally rugose.

\section{FRUIT TYPE AND DESCRIPTION:}

Cucurbita fruits are practically classified as berries; they are mostly differed by shape, colour, and size. The flower is Elliptic cylinder, oval, globular, heart shaped and curved neck on both ends. There are dozens of varieties of pumpkins that come in traditional shades of orange, but alsored, green, blue, yellow, white and tan. The length is from $6 \mathrm{~cm}$ to $72 \mathrm{~cm}$ and width from 10 to $50 \mathrm{~cm}$. The skin can be smooth, warty, wrinkled and have longitudinal ridges. Pumpkins basically weighs from $300 \mathrm{mg}$ to $50 \mathrm{~kg}$. Each fruit contains several seeds.

\section{SEED DESCRIPTION:}

Pumpkin seeds are edible, flat, oval-shaped green seeds. The seeds are typically flat and asymmetrically oval, have a white outer husk, and are light green in color after the husk is removed. It contains $30-60 \%$ oil. Seeds size vary from $1.5 \mathrm{~cm}$ $3 \mathrm{~cm}$ long, 0.5 to $2 \mathrm{~cm}$ wide. Seeds weighs approximately $50 \mathrm{~g} / 100$ seeds.

\section{CHEMICAL COMPOSITION:}

Carotenoids are highly present in the fruit of these plants, namely $\alpha$-carotene, $\beta$-carotene, $\zeta$-carotene, neoxanthin, violaxanthin, lutein, zeaxanthin, taraxanthin, luteoxanthin, auroxanthine, neurosporene, flavoxanthin, 5,6,5',6'-diepoxy- $\beta$ - 
carotene, phytofluene, $\alpha$-cryptoxanthin and $\beta$ cryptoxanthin. ${ }^{[4]}$

the shoots and buds showed positive results. Sreeramulu and Raghunath ${ }^{[5]}$ reported that average total phenolic content of $C$. maxima was $46.43 \mathrm{mg}$ gallic acid equivalent (GAE)/100 g. In another study, C. maxima was analyzed for its flavonoid content and kaempferol was found to be the only flavonoid in this species at a concentration of 371.0 $\mathrm{mg} / \mathrm{kg}$ of dry weight ${ }^{[6]}$. Tyrosol, vanillic acid, vanillin, ferulic acid and luteolin. Among them, tyrosol was the most abundant compound ranging from $1.6 \mathrm{mg} / \mathrm{kg}$ to $17.7 \mathrm{mg} / \mathrm{kg}$.

\section{PHARMACOLOGICAL ACTION ANTIMICROBIAL ACTIVITY}

Muruganantham et.al., reported the antimicrobial activity of Cucurbita maxima plant. Ethyl acetate extraction of C. maxima flowers shows a important antibacterial activity against bacteria and fungi. Disc diffusion method is used to measure the bacterial and fungal growth and it is compared to standards Chloramphenicol (bacterial growth) and fluconazole (bacterial growth). Cucurbita shows greater (zone of inhibition) antimicrobial potential. Alya et al., reported the antibacterial activity on Gram positive and Gram-negative bacteria Cucurbita pepo. Plate method is used to identify the anti-microbial activity of flavonoid extract of Cucurbita and it is compared with standards. It has greater potential of anti-microbial activity.

\section{ANTI OXIDANT AND ANTI \\ INFLAMMATORY}

N. Muruganantham et al., reported Ethyl acetate extraction of Cucurbita maxima flowers has Antioxidant and anti-inflammatory. Azino-bis 3-ethyl benzthiazoline-6-sul- phonic acid (ABTS) assay is carried out to evaluate anti-oxidant by Diphenyl 1picryl hydrazyl solution. Human blood cell membrane stabilization method and Inhibition of albumin denaturation method is used to determine anti-inflammatory activity. This study reports Cucurbita has greater potential and contains antioxidants and anti-inflammatory activity.

\section{ANXIOLYTIC ACTIVITY}

Indu Arora et al., reported Anxiolytic activity of ethanolic and ethyl acetate extracts of Cucurbita moschata seeds (CM) in mice. Elevated plus Maze and Light Dark Box method is used to evaluate the anxiolytic potential of ethanolic and ethyl acetate extracts of Cucurbita moschata seeds after the extract given to mice for 14days. Rota rod method is used to obtain the motor coordination behaviour. Extracts reveals greater anxiolytic activity but ethanolic extract of Cucurbita moschata seeds (200 $\mathrm{mg} / \mathrm{kg}$ ) has some more potential than other when compared with Alprazolam.

\section{ANTIGIARDIAL ACTIVITY}

Mona et al., reported antigiardial activity of Cucurbita maxima D, Cucurbita pepo $\mathrm{L}$ and Lagenaria siceraria. petroleum ether extract of $\mathrm{C}$. maxima seeds shows $100 \%$ mortality and petroleum ether extract of L. siceraria shows $96 \%$. The drug Metronidazole is used as a standard. Petroleum ether extract of Cucurbita maxima results greater potential of antigiardial activity.

\section{ANTIPYRETIC ACTIVITY}

Ankana et al., reported Anti pyretic, antiinflammatory and analgesic activity by isolating stigmasterol by extraction of Cucurbita maxima seeds using methanol. carrageenan-induced hind paw edema method is used to determine antiinflammatory activity. Eddy's Hot plate method, Tail Flick Method and Acetic Acid Induced Writhing Method is used to determine analgesic activity. Diclofenac is used as standard drug. Pyrexia induced method is used to investigate anti pyretic activity by Brewer's yeast. Paracetamol is used as standard drug. The isolated compound stigmasterol shows greater potential as anti-pyretic, anti-inflammatory and analgesic activity.

\section{ANTI FILARIAL ACTIVITY}

Justin et al., reported Anti filarial activity of C.pepo. Extract obtained by ethanol solvent of C.pepo seeds and leaves is tested against cattle parasite nematode Onchocercaochengi in a nutrient medium at $37^{\circ} \mathrm{c}$ and mortality checked at regular intervals 24,48 and 72 hours. Various concentration of extract is treated with O.ochengi. Ivermectin is used as standard drug. C. pepo ovifera extract has greater antifilarial activity. This report suggest that the plant species has anthelmintic potential. ${ }^{[7]}$

\section{ANTI ULCER ACTIVITY}

Sentu et al., reported Anti-ulcer activity of Ripe fruit Curcubita pepo. Aspirin is given to albino rats and potential decline in Alkaline phosphatase activity is compared with extract. Mucosal thickness improvement also investigated. Greater anti-ulcer potential of Cucurbita is identified when extract is treated with albino rats for continue 14 days results in increase in AP activity and mucosal thickness. ${ }^{[8]}$

\section{ANTI DIABETIC ACTIVITY}

Ata Mahmoodpoor et al., reported Anti diabetic activity of Cucurbita maxima in diabetic patients in Intensive care unit. lyophilized powder of $\mathrm{C}$. maxima is given to 20 persons in Hospital. Three days before blood glucose is observed. After the drug given blood glucose level is recorded after three days. Before the extract administration the blood glucose level is recorded as $214.9 \pm 55.7$ $\mathrm{mg} / \mathrm{dl}$. After the administration the blood glucose level declined to $178.4 \pm 36.1 \mathrm{mg} / \mathrm{dl}$. It shows 
Cucurbita maxima has greater anti diabetic potential. ${ }^{[9]}$

\section{NEUROPROTECTIVE ACTIVITY}

Sinha et al., reported neuroprotective activity of C.maxima by investigating cholinesterases (acetylcholinesterase and butyrylcholinesterase), monoamine oxidase (MAO) and $\mathrm{Na}^{+} / \mathrm{K}^{+}$ATPase activities of ethanolic and hexane extract. Ethanolic and hexane extract of C.maxima retards the acetylcholinesterase and butyrylcholinesterase. Donepezil is used as a standard. Quercetin rich in Cucurbita maxima is observed. The extract shows best cholinesterase activity. ${ }^{[10]}$

\section{ANTI CANCER ACTIVITY}

Prerona Saha et al., reported the anticancer activity of methanol extract of Cucurbita maxima in mice with Ehrlich Ascites Carcinoma. Extract treated with mice inoculated with carcinoma cells at doses 200 and $400 \mathrm{mg} / \mathrm{kg}$. 5-Fluorouracil with dose 20 $\mathrm{mg} / \mathrm{kg}$ is used as a standard for 9 days. hematological parameters, biochemical estimations, antioxidant assay of liver tissue and in vitro cytotoxicity is investigated for the extract to determine tumor growth response including increase in life span. Study revealed that the greater anti-cancer activity because of cytotoxicity and antioxidant properties.

SvjetlanaMedjakovic et al., investigated the hydro ethanolic extract of pumpkin seeds from Cucurbita pepo L. subsp. pepo var. Human androgen receptor, estrogen receptor and progesterone receptor's transactivation activity were investigated in invitro yeast assay. Cell viability tests with prostate cancer cells, breast cancer cells, colorectal adenocarcinoma cells and a hyperplastic cell line from benign prostate hyperplasia tissue were performed. A cell growth inhibition of $\sim 40-50 \%$ was evaluated for all cell lines, with the exclusion of HDF-5, which indicates with 20\% lower cell growth inhibition. A steroid-hormone receptor independent growth inhibiting activity was observed. Because of less androgenic activity, pumpkin seed extract can be mentioned as safe for the prostate.

\section{DISINTEGRATING PROPERTY}

Rishabha et al, reported Disintegrating property of C.maxima powders by formulating Diclofenac tablets. Tablet is formulated by wet granulation method and filler used in formulation is microcrystalline cellulose. Various percentage 2.5, 5, 7.5 and $10 \%$ (w/w) of Cucurbita maxima pulp powder of disintegrate is used. Standardisation of tablets is performed by evaluating thickness, hardness, friability, weight variation, drug content, disintegration time and drug dissolution. Study revealed Cucurbita has greater disintegrate potential and in future it will be used as disintegrate in formulations. ${ }^{[11]}$

\section{ANTI HYPERTENSIVE EFFECT}

Madhavi et al., reported Anti-hypertensive effect of methanolic extract Cucurbita maxima. Rat is used in in vivo studies and the impact on blood pressure is recorded for normal $\mathrm{BP}$ rats and hypertensive rats. Noninvasive blood pressure measurement is used to calculate systolic, diastolic, mean blood pressures and heart rate. The extract at both doses (200 and $400 \mathrm{mg} / \mathrm{kg}$ ) shows a notable decline in blood pressure and heart rate of rats having normal blood pressure. When the dose of $200 \mathrm{mg} / \mathrm{kg}$ is given, it shows less notable effect than $400 \mathrm{mg} / \mathrm{kg}$. At the dose $400 \mathrm{mg} / \mathrm{kg}$, the extract shows a greater potential effect was selected for antihypertensive effect in hypertensive rats. A greater potential antihypertensive was investigated at $400 \mathrm{mg} / \mathrm{kg}$ in both hypertensive models. But also, a non-notable decline in alanine aminotransferase, Aspartate aminotransferase, but significant decline in total cholesterol, triglycerides, LDL and increase in HDL levels were evaluated in the serum of the extract treated animals. The methanolic extract of Cucurbita maxima has safer effective principles which has potential on both hypotensive and antihypertensive effects in normal and hypertensive animal models respectively.

\section{ANTI HYPERLIPIDEMIC ACTIVITY}

Devesh et al., reported antihyperlipidemic activity of seed extract of Cucurbita maxima. Diabetes is induced in rats by streptozotocin and extract is given at the dose of $200 \mathrm{mg} / \mathrm{kg}$ to the diabetic rats and monitored for four weeks. Monitored parameters are total cholesterol, triglycerides, high density lipoprotein cholesterol, low density lipoprotein cholesterol, very low-density lipoprotein cholesterol, Urine Sugar, Urine Protein and Body Weight. The highest decline possesses by extract in case of total cholesterol, triglycerides, high density lipoprotein cholesterol, low density lipoprotein cholesterol, very low-density lipoprotein cholesterol levels were evaluated to be $53.0,56.9,75.6$ and $56.9 \%$, respectively in case of STZ induced diabetic rats. The report shows both antihyperlipidemic potential of Cucurbita seed extract and shows the hypoglycemic and antidiabetic activity.

\section{ANTICOAGULANT ACTIVITY}

Li Liang et al,, reported anticoagulant activity of pumpkin (Cucurbita pepo, Lady Godiva) polysaccharide. The research shows Sulfated modification of Cucurbita has significant anticoagulant activity. Therefore, it suggests the anticoagulant properties of Cucurbita and future research work should be done in this zone. It 
suggested Cucurbita has some anti platelet activity also. ${ }^{[12]}$

\section{DIURETIC ACTIVITY}

Sampath et al., reported diuretic Activity of Hydro alcoholic extract of C.maxima. Physico parameters such as Ash values, extractive values and loss on drying were evaluated to confirm quality. Soxhlet apparatus is used for extraction. Rat is administered with the extract at the doses $150 \mathrm{mg} / \mathrm{kg}$ and $300 \mathrm{mg} / \mathrm{kg}$. Acetazolamide is used as a standard drug. For both standard drug administrated rats and test sample administrated rats urine volume and electrolytes are evaluated. The extract possesses great Diuretic potential at dose of $300 \mathrm{mg} / \mathrm{kg}$ while compared to standard. ${ }^{[13]}$

\section{APHRODISIAC SYNERGETIC ACTIVITY}

Herbals produces synergism while they are used as polyherbal formulation. Himanshu et al., [14] repoted aphrodisiac activity of polyherbal formulations as suspension formulated by Tribulus terrestris, Curculigoorchioides, Allium tuberosum, Cucurbita pepo, Elephant creeper, Mucuna pruriens, and Terminalia catappa by Albino rats. The extract is given at different doses 150, 300, and $600 \mathrm{mg} / \mathrm{kg}$. Sildenafil citrate is used as a standard drug and monitored for 3 weeks. For the first week Mating action parameters are monitored in male rats. The mating performance, hormonal analysis, sperm count, and testes-body weight ratio are observed after the completion of drug bio availability. The polyherbal formulation possess a greater aphrodisiac activity and much increase in mating performance, serum hormonal levels, sperm count, and testes-body weight ratio and matched with standard drug. At the dose of $600 \mathrm{mg} / \mathrm{kg}$ of polyherbal formulation shows potential in parameters with the standard used.

\section{ANTIOXIDANT SYNERGETIC ACTIVITY}

Shelke et al., reported Antioxidant activity by formulating polyherbal formulation by four herbs Cucurbita maxima, Helianthus annus, Spinach oleracea and Beta vulgaris. Tincture is formulated by $90 \%$ of ethanol. The antioxidant activity of the formulation was evaluated by DPPH free radical scavenging method. The results reported that the formulation has greater antioxidant activity at a dose of $100 \mu \mathrm{g} / \mathrm{ml}$ when it was matched with ascorbic acid as standard drug. ${ }^{[15]}$

\section{HEPATO PROTECTIVE ACTIVITY}

Adepoju et al., reported Nephroprotective and hepatoprotective effect of C.pepo by using Wistar albino rats by Hematological and biochemical parameters. Cucurbita pepo pulverized seeds are given as food in various amounts as general diet. Blood collection and organ investigations are evaluated by standard laboratory tests. The result shows Cucurbita pepo seeds potentially improves these parameters with beneficial way on the vital organs and blood. The amount of the platelets, white blood cells and eosinophil were improved in numbers, while it declines the amount of the neutrophils, packed cell volume and lymphocytes. It importantly increases mean weights of the liver and the kidneys. The seeds possess a nephro-and hepato-protective activity. ${ }^{[16]}$

\section{ANTI-OSTEOPOROTIC ACTIVITY}

Sindhura et al., reported Anti-osteoporotic activity of Cucurbita pepo seed powder and lowlevel laser beam on glucocorticoid induced osteoporosis in rats. The extract is given for continuous 8 weeks. Locomotor actions are observed by Actophotometer, anxiety observed by elevated plus maze method and body weight are recorded. Calcium, Phosphorous and creatinine level are measured in urine. ALP, Calcium, phosphorous, creatinine level from blood also measured. Mechanical parameters of bone observed at the $8^{\text {th }}$ week. The extract and laser beam decreases the body weight, increases the Locomotor activity and lowers the anxiety. Calcium, phosphorous and creatinine decreased in urine and increased in blood. This study shows that Cucurbita and Laser beam possess Anti osteoporotic potential. ${ }^{[1]}$

\section{CONCLUSION}

According to the literature, the selected plant species showed significant medicinal values which are used traditionally to treat different diseases for centuries. The Cucurbitais available in many countries and the local community traditionally used it to treat many diseases and also used it as edible. The bioactive ingredients were isolated from the fruits, leaves, seeds, roots and showed several pharmacological activities. The prepared fresh, dry fruit, leaves, and their paste also showed significant activity against antifungal, antimicrobial, antioxidant, antiulcer, anxiolytic, antigiardial, antipyretic, antifilarial, antidiabetic, neuroprotective, anti-cancer, antihypertensive, antihyperlipidemic, diuretic, hepatoprotective and anti-osteoporotic activity. Therefore, the investigation is focused on the selected plant species for the discovery of the new medicines to treat different diseases. Our present review aims to identify the present status of the phytochemical and pharmacological activities of the locally grown Cucurbita and it will help in many research. The current research would support further research initiatives in the future to further isolate new drugs that would benefit the pharmaceutical, agrochemical, and cosmetics industries. 
TABLE 1:

\begin{tabular}{|c|c|c|}
\hline S.No & Cucurbita group & Taxa \\
\hline 1. & Argyrosperma category & $\begin{array}{l}\text { C. argyrosperma } \\
\text { C. argyrosperma ssp. sororia }\end{array}$ \\
\hline 2. & Maxima category & $\begin{array}{l}\text { C. maxima Duchesne } \\
\text { C. maxima ssp. andreana }\end{array}$ \\
\hline 3. & Pepo category & $\begin{array}{l}\text { C. pepo L } \\
\text { C. pepo ssp. fraterna } \\
\text { C. pepo ssp. texana }\end{array}$ \\
\hline 4. & Okeechobeensis category & C. okeechobeensis \\
\hline 5. & Digitata category & $\begin{array}{l}\text { C. digitata } \\
\text { C. cordata } \\
\text { C. palmata }\end{array}$ \\
\hline 6. & Foetidissima category & $\begin{array}{l}\text { C. foetidissima } \\
\text { C. pedatifolia } \\
\text { C. scabridifolia } \\
\text { C. radicans Naudin }\end{array}$ \\
\hline 7. & $\begin{array}{l}\text { Species with no defined } \\
\text { category }\end{array}$ & $\begin{array}{l}\text { C. ecuadorensis } \\
\text { C. lundelliana } \\
\text { C. ficifolia Bouché } \\
\text { C. moschata } \\
\text { Duchesne }\end{array}$ \\
\hline
\end{tabular}

\section{REFERENCE}

1. T. Sampath Kumar, P. Muthusamy, R. Radha, K. Ilango. Formulation and Evaluation of in vitro antidiabetic Polyherbal tablets form some traditional used Herbs. The Journal of Phytopharmacology. ISSN 2320-480X. JPHYTO 2021; 10(3): 173-179.

2. S Muthuraj, MK Seeni, P Muthusamy, T Sampathkumar. Review on Scope of Pharmacognosy graduate in various government research institute in India. . The Journal of Phytopharmacology. ISSN 2320480X JPHYTO 2021; 10(4): 266-271.

3. T. Sampath kumar1, p. Muthusamy1, r. Radha1 and k. Ilango. A review on phytochemical pharmacological and pharmacognostical profile of horse gram. World Journal of Pharmaceutical Research. Volume 8, Issue 5, 1436-1449. ISSN 2277- 7105.

4. Azevedo-Meleiro C.H., Rodriguez-Amaya D.B. Qualitative and quantitative differences in carotenoid composition among Cucurbita moschata, Cucurbita maxima, and Cucurbita pepo. J. Agric. Food Chem.2007; 55:4027-4033.

5. Sreeramulu D., Raghunath M. Antioxidant activity and phenolic content of roots, tubers and vegetables commonly consumed in India. Food Res. Int.2010; 43:1017-1020.

6. Koo M.H., Suhaila M. Flavonoid (Myricetin, Quercetin, Kaempferol, Luteolin and Apigenin) Content of Edible Tropical Plants. J. Agric. Food Chem.2001; 49:3106-3112..

7. Justin kalmobe, Dieudonne Ndjonka, Jacqueline vildinadikti, Eva Liebau. Antifilarial Activity of Cucurbita pepo ovifera var ovifera (Cucurbitaceae) on Onchocercaochengi Adult Worms. Journal of Pharmaceutical Research International, Page 1-8

8. Sarkar S, Buha D. Effect of ripe fruit pulp extract of Cucurbita pepo Linn. in aspirin induced gastric and duodenal ulcer in rats. Indian J Exp Biol. 2008 Sep;46(9):639-45. PMID: 18949893.

9. Ata Mahmoodpoor, Mahsa Medghalchi, Hossein Nazemiyeh, Parina Asgharian, Kamran Shadvar, and Hadi Hamishehkar, Effect of Cucurbita Maxima on Control of Blood Glucose in Diabetic Critically Ill Patients. Advanced Pharmaceutical bulletin.2018 Jun; 8(2): 347-351.

10. S.Sinha, B.Kumar, S.Luqman, D.K.Singh. Neuroprotective potential of Cucurbita maxima Duchesne ex Poir, Caeselpeniabunduc (L.) Roxb and Bombax ceiba Linn extracts. South African journal of Botany. Volume 120, January 2019, Pages 319-325.

11. Rishabha Malviya, Pranati Srivastava, Bansal Mayank. Preparation and evaluation of disintegrating properties of Cucurbita maxima pulp powder Indian Journal of Pharmaceutical Sciences 2(1):395-399. January 2010

12. Li Liang, Le Ao, Tao Ma, Yuan Ying Ni. Sulfated modification and anticoagulant activity of pumpkin (Cucurbita pepo, Lady Godiva) polysaccharide. International Journal of Biological Macromolecules 106:447-455. 
13. Venkattapuram Sampath Saravanan and Sellimuthu Manokaran Physico-chemical studies and evaluation of diuretic activity of Cucurbita maxima. Bangladesh J Pharmacol. 2012; 7: 277-280.

14. Himanshu Bhusan Sahoo Subhangkar Nandy Aswini Kumar Senapati Sarada Prasad Sarangi Saroj Kumar Sahoo. Aphrodisiac activity of polyherbal formulation in experimental models on male rats. National Library of Medicine. 2014 Apr;6(2):120-6.

15. DP Shelke, GR Shendarkar, AK Daswad, JG Pohare, SN Wangawar and AB Roge. Design and development of polyherbal formulation with antioxidant potential. Journal of Medicinal Plants Studies Corpus ID: 135952455. Published 2017.

16. G K A Adepoju, A A Adebanjo. Effect of consumption of Cucurbita pepo seeds on hematological and biochemical parameters. African Journal of Pharmacy and Pharmacology 267261130. January 2011.

17. G. Sindhura and K. P. S. Gowda. Anti-osteoporotic activity of Cucurbita pepo and low-level laser beam on glucocorticoid induced osteoporosis in rats. International journal of pharmaceutical sciences and research. ISSN: 0975-8232. 